\title{
Prediksi Jumlah Kunjungan Wisatawan Mancanegara di Indonesia dengan Menggunakan Metode ARIMA Box-Jenkins dan Jaringan Syaraf Tiruan
}

\author{
Artanti Indrasetianingsih ${ }^{(1)}$, Ika Damayanti $^{(2)}$ \\ (1),(2)Universitas PGRI Adi Buana \\ Jl. Dukuh Menanggal XII/4 Surabaya \\ e-mail: artanti.indra@unipasby.ac.id, ika.damayanti@unipasaby.ac.id
}

\begin{abstract}
ABSTRAK
Salah satu bidang yang banyak diperebutkan di era Masyarakat Ekonomi Asia (MEA) adalah bidang pariwisata. Indonesia sebagai bagian dari Negara-negara ASEAN (Association of South East Asian Nations), merupakan negara yang kaya akan budaya dan memiliki banyak destinasi wisata yang patut diperhitungkan baik di tingkat regional maupun internasional. Jumlah kunjungan wisatawan mancanegara (wisman) ke Indonesia mengalami peningkatan dari tahun ke tahun. Peningkatan jumlah kunjungan wisatawan mancanegara tersebut ternyata masih menempatkan Indonesia di posisi ke empat di negaranegara ASEAN pada tahun 2012 dan 2014. Pada tahun 2019, Kementrian Pariwisata (Kemenpar) menargetkan jumlah wisman yang berkunjung ke Indonesia sebesar 20 juta. Perlu adanya sinergi dari pemerintah dan masyarakat, baik dari pemerintah pusat maupun daerah. Selain itu juga diperlukan adanya perencanaan dan strategi promosi yang tepat. Salah satu cara untuk memperoleh gambaran tentang jumlah kunjungan wisatawan mancanegara ke Indonesia adalah melakukan peramalan dengan menggunakan analisis deret runtun waktu. Tujuan dari penelitian ini adalah untuk memperoleh prediksi jumlah wisatawan mancanegara yang berkunjung ke Indonesia tahun 2017 s.d tahun 2019 dengan menggunakan metode ARIMA Box-Jenkins dan Jaringan Syaraf Tiruan, serta membandingkan hasil prediksi jumlah kunjungan wisatawan mancanegara ke Indonesia hasil menggunakan ARIMA Box-Jenkins dengan Jaringan Syaraf Tiruan. Data yang digunakan adalah data bulanan jumlah kunjungan wisman ke Indonesia mulai bulan Januari 2010 sampai bulan Juni 2017. Hasil yang diperoleh dari analisis ARIMA Box Jenkins adalah model ARIMA $(0,1,1)(0,0,2)^{12}$, sedangkan hasil analisis menggunakan Jaringan Syaraf Tiruan algoritma backpropagation yang digunakan adalah dengan hidden layer 3. Hasil perhitungan nilai kesalahan peramalan dengan MAPE, MAD dan MSE didapatkan bahwa metode ARIMA mempunyai nilai MAD = 8.069,81 dan MSE = 9.134.981.806,98 yang lebih rendah dibanding metode Jaringan Syaraf Tiruan, maka metode yang lebih baik digunakan untuk meramalkan jumlah kunjungan wisman ke Indonesia adalah ARIMA $(0,1,1)(0,0,2)^{12}$.
\end{abstract}

Kata kunci : ARIMA Box-Jenkins, jaringan syaraf tiruan, prediksi, wisatawan mancanegara

\begin{abstract}
One of the most contested fields in the era of Asian Economic Community (AEC) is the field of tourism. Indonesia as part of the ASEAN countries, is a country rich in culture and has many tourist destinations worth considering both at regional and international levels. The number of foreign tourist arrivals to Indonesia has increased from year to year. Increasing the number of foreign tourists visiting it was still put Indonesia in the fourth position in ASEAN countries in 2012 and 2014. In 2019, the Ministry of Tourism targets the number of foreign tourists visiting Indonesia by 20 million. It needs synergy from government and society, both from central and local government. It is also necessary to have the right planning and promotion strategy. One way to get an idea of the number of foreign tourist arrivals to Indonesia is to forecast by using time series analysis. The purpose of this study is to obtain predictions of the number of foreign tourists who visit Indonesia 2017 s.d year 2019 using ARIMA Box-
\end{abstract}


Jenkins and Neural Network methods, and comparing the predicted result of the number of foreign tourist arrivals to Indonesia using ARIMA Box-Jenkins with Artificial Neural Network. The data used is monthly data on the number of visits of foreign tourists to Indonesia from January 2010 until June 2017. Results obtained from ARIMABox-Jenkins analysis is ARIMA $(0,1,1)(0,0,2){ }^{12}$ model, while the result of analysis using Artificial Neural Network backpropagation algorithm used is with hidden layer 3. The result of calculation of forecasting error value with MAPE, MAD and MSE found that ARIMA method has MAD value $=8.069,81$ and $M S E=9,134,981,806,98$ which is lower than Artificial Neural Network method, hence better method is used to predict the number of visits of foreign tourists to Indonesia is $\operatorname{ARIMA}(0,1,1)(0,0,2){ }^{12}$.

Keywords : ARIMA Box-Jenkins, artificial neural networks, predictions, foreign tourists

\section{PENDAHULUAN}

Salah satu bidang yang banyak diperebutkan di era Masyarakat Ekonomi Asia (MEA) adalah bidang pariwisata. Indonesia sebagai bagian dari Negara-negara ASEAN (Association of South East Asian Nations), merupakan negara yang kaya akan budaya dan memiliki banyak destinasi wisata yang patut diperhitungkan baik di tingkat regional maupun internasional.

Jumlah kunjungan wisatawan mancanegara ke Indonesia mengalami peningkatan dari tahun ke tahun. Peningkatan jumlah kunjungan wisatawan mancanegara tersebut ternyata masih menempatkan Indonesia di posisi ke empat di negara-negara ASEAN. Berdasarkan data www.worldstatistics.org, jumlah kunjungan wisatawan mancanegara (wisman) pada tahun 2012, Indonesia menempati posisi keempat $(8.044 .000$ wisman) di ASEAN. Jumlah tersebut di bawah Negara Malaysia (25.033.000 wisman), Thailand (22.354.000 wisman), dan Singapura (11.098.000 wisman). Pada tahun 2014 jumlah wisman berkunjung ke Malaysia masih yang tertinggi, yaitu sebesar 27.437.000 wisman, sedangkan Indonesia masih menempati posisi keempat, yaitu sebesar 9.435.000 wisman.

Sepanjang tahun 2011 menurut data yang dirilis BPS (Badan Pusat Statistik), sektor pariwisata menjadi penyumbang devisa negara terbesar kelima di Indonesia di bawah migas, batu bara, minyak kelapa sawit, dan karet olahan, yaitu sebesar 8,554 miliar dolar AS. Pada tahun 2014 sektor pariwisata mampu menyumbang devisa negara sebesar 10 miliar dolar AS.

Kementrian Pariwisata (Kemenpar) menargetkan jumlah kunjungan wisman ke Indonesia pada tahun 2019 sebesar 20 juta. Perlu adanya sinergi dari pemerintah dan masyarakat, baik dari pemerintah pusat maupun daerah. Selain itu juga diperlukan adanya perencanaan dan strategi promosi yang tepat.
Peramalan dengan menggunakan analisis deret runtun waktu merupakan salah satu cara untuk memperoleh gambaran tentang jumlah kunjungan wisman ke Indonesia. Metode ARIMA BoxJenkins dan Jaringan Syaraf Tiruan merupakan bagian dari analisis deret runtun waktu. Penelitian sebelumnya yang berkaitan dalam meramalkan jumlah kunjungan wisman ke Indonesia adalah penelitian yang dilakukan oleh Wiradinata, S.A. (2011). Pada penelitian tersebut meramalkan jumlah kunjungan wisman ke Provinsi Riau dan model ARIMA yang diperoleh adalah $\operatorname{SARIMA}(0,1,1)(0,1,1)^{12}$. Selain itu penelitian yang dilakukan oleh Rukini, et.al (2015) tentang peramalan jumlah kunjungan wisman ke Bali tahun 2019 dengan menggunakan metode ARIMA. Hasil yang diperoleh adalah ramalan jumlah kunjungan wisman ke Bali Tahun 2019 sebesar 5.07 juta (masih di bawah target minimal tahun 2019, yaitu sebesar 8 juta).

Data yang digunakan dalam penelitian ini adalah data bulanan jumlah kunjungan wisman ke Indonesia dari tahun 2010 sampai bulan Juni 2017. Tujuan dari penelitian ini adalah untuk memperoleh prediksi jumlah wisatawan mancanegara yang berkunjung ke Indonesia tahun 2017 s.d tahun 2019 dengan menggunakan metode ARIMA Box-Jenkins dan Jaringan Syaraf Tiruan, serta membandingkan hasil prediksi jumlah kunjungan wisatawan mancanegara ke Indonesia hasil menggunakan ARIMA Box-Jenkins dengan Jaringan Syaraf Tiruan.

\section{METODE PENELITIAN}

Data yang digunakan dalam penelitian ini adalah data sekunder yang diperoleh dari website Kemenpar RI www.kemenpar.go.id , yaitu data bulanan jumlah kunjungan wisatawan mancanegara ke Indonesia mulai periode Januari 2010 sampai 
dengan Juni 2017. Data penelitian dibagidua, yaitu data in sample (Januari 2010 s.d Mei 2016) dan data out sample (Juni 2016 s.d Juni 2017).

Variabel yang digunakan pada penelitian ini ada tiga, yaitu jumlah kunjungan wisatawan mancanegara di Indonesia $\left(Y_{t}\right)$, variable jumlah kunjungan wisatawan mancanegara di Indonesia pada bulan ke-(t-1) $\left(Y_{t-1}\right)$, dan variabel jumlah kunjungan wisatawan mancanegara di Indonesia pada bulan ke- $(\mathrm{t}+1)$.

Metode analisis data yang digunakan dibagi menjadi empat tahap, yaitu

1. Analisis deskriptif

2. Analisis menggunakan ARIMA Box-Jenkins. Tahapan-tahapan dalam melakukan analisis menggunakan ARIMA Box-Jenkins adalah identifikasi model, estimasi dan pengujian parameter, diagnostic checkhing (pemeriksaan asumsi residual berdistribusi normal dengan uji Kolmogorov Smirnov dan asumsi white noise dengan L-jung Box), melakukan peramalan dan menghitung Ukuran kesalahan peramalan MAPE, MAD dan MSE.

3. Analisis menggunakan Jaringan Syaraf Tiruan, melakukan peramalan dan menghitung nilai kesalahan peramalan MAPE, MAD dan MSE.

4. Melakukan perbandingan metode ARIMA dan Jaringan Syaraf Tiruan dengan kriteria MAPE, MAD dan MSE.

\section{HASIL DAN PEMBAHASAN}

\section{A. Deskriptif Data}

Berdasarkan Gambar 1 dapat diketahui bahwa jumlah wisatawan mancanegara yang berkunjung ke Indonesia terus mengalami peningkatan dari tahun 2010 sampai dengan Mei 2016. Deskriptif dari jumlah kunjungan wisatawan mancanegara dapat dilihat pada Tabel 1 . Tabel 1 bahwa rata-rata jumlah kunjungan wisatawan mancanegara per bulan ke Indonesia terus mengalami peningkatan. Rata-rata pada tahun 2016 meskipun masih sampai bulan Mei 2016 menunjukkan nilai rata-rata tertinggi, yaitu sebesar adalah 939.774 wisatawan.

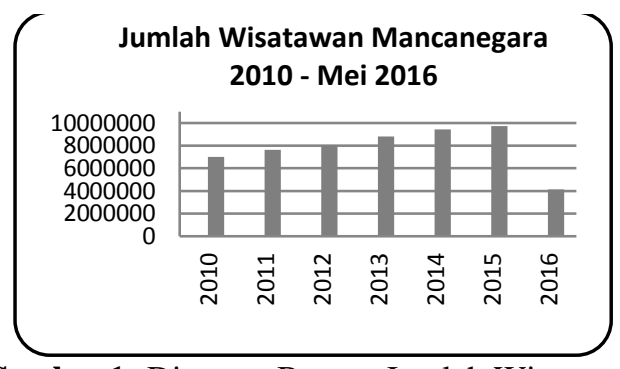

Gambar 1. Diagram Batang Jumlah Wisman 2010 - Mei 2016

Tabel 1. Deskriptif Jumlah Wisman

\begin{tabular}{|l|l|l|l|l|l|}
\hline Tahun & Mean & StDev & Median & Min & Max \\
\hline 2010 & 583.579 & 46.457 & 590.386 & 493.799 & 658.476 \\
\hline 2011 & 637.478 & 58.902 & 635.578 & 548.821 & 745.451 \\
\hline 2012 & 670.372 & 44.850 & 671.093 & 592.502 & 766.966 \\
\hline 2013 & 733.511 & 70.084 & 722.610 & 614.328 & 860.655 \\
\hline 2014 & 786.284 & 57.921 & 771.409 & 702.666 & 915.334 \\
\hline 2015 & 867.230 & 54.428 & 862.387 & 785.973 & 986.519 \\
\hline $\left.2016^{*}\right)$ & 939.774 & 52.068 & 956.381 & 851.462 & 983.810 \\
\hline
\end{tabular}

Keterangan : *) sampai dengan Mei 2016

\section{B. Analisis Model ARIMA}

Analisis model ARIMA dilakukan diawali dengan identifikasi model, yaitu dengan membuat plot time series dan plot ACF untuk mengetahui apakah data penelitian sudah stasioner atau belum. Gambar 2 menunjukkan bahwa data belum stasioner dalam mean, hal ini juga terlihat pada plot ACF data pada yang menurun secara lambat (Gambar 3).

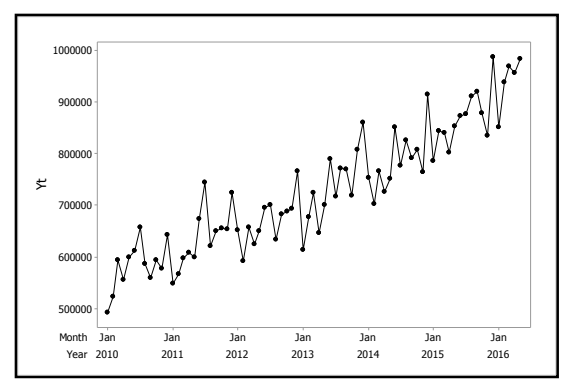

Gambar 2. Plot time series data wisman 


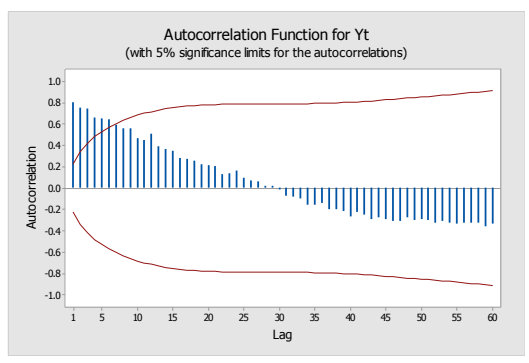

Gambar 3. Plot ACF data wisman

Data yang belum stasioner dalam mean non musiman, dilakukan differencing 1. Gambar 4 merupakan gambar plot time series setelah dilakukan differencing 1 non musiman, gambar tersebut sudah menunjukkan data telah stasioner.

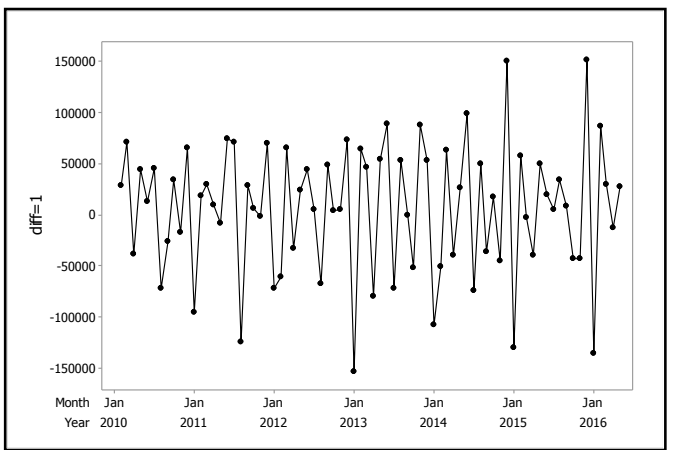

Gambar 4. Plot time series setelah didifference 1

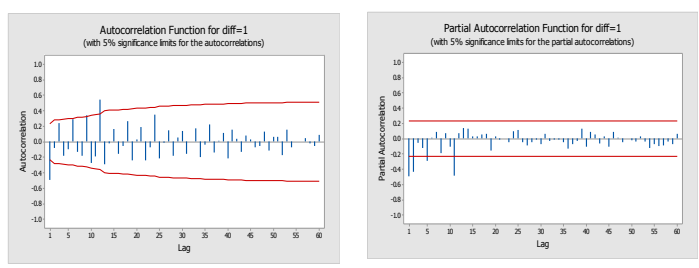

Gambar 5. Plot ACF, PACF setelah didifference 1

Berdasarkan Gambar 5 maka dilakukan identifikasi model awal dari data dan menunjukkan adanya musiman 12, karena pada lag 12 nilai ACF dan PACF nya signifikan, maka dugaan modelnya adalah ARIMA $(0,1,1)(0,0,2)^{12}$

Hasil estimasi parameter dapat dilihat pada Tabel 2 , menunjukkan bahwa semua parameter model signifikan pada $\alpha=5 \%$.

Tabel 2. Hasil Estimasi Parameter

\begin{tabular}{|l|r|r|r|}
\hline parameter & \multicolumn{1}{|c|}{ Koef. } & \multicolumn{1}{|c}{$\boldsymbol{P}$-value } & \multicolumn{1}{|c|}{ Keterangan } \\
\hline$\theta_{1}$ & 0,7169 & 0,000 & Signifikan \\
\hline$\Theta_{12}$ & $-0,7743$ & 0,000 & Signifikan \\
\hline
\end{tabular}

\begin{tabular}{|l|l|l|l|}
\hline$\Theta_{24}$ & $-0,6481$ & 0,000 & Signifikan \\
\hline
\end{tabular}

Langkah selanjutnya adalah diagnostic checking. Hasilnya uji L-Jung Box menunjukkan bahwa semua nilai $p$-value $>\alpha=5 \%$, hal ini menerangkan bahwa residual model telah memenuhi asumsi white noise. Uji asumsi residual berdistribusi normal dilakukan dengan uji kolmogorov smirnov, hasilnya menunjukkan bahwa residual telah memenuhi asumsi berdistribusi normal, karena nilai $p$-value yang diperoleh sebesar 0,150 , nilai tersebut lebih besar dari $\alpha=5 \%$.

Hasil peramalan menggunakan model ARIMA $(0,1,1)(0,0,2)^{12}$ dapat dilihat pada Tabel 6. Persamaan model ARIMA $(0,1,1)(0,0,2)^{12}$ yang diperoleh adalah sebagai berikut :

$Y_{t}=-0,2831 Y_{t-1}+0,7169 Y_{t-2}+a_{t}+0,7743 a_{t-12}+0,648 a_{t-24}$

Langkah selanjutnya adalah melakukan peramalan dan menghitung nilai kesalahan peramalan, yaitu nilai MSE $=9.134 .981 .806,98$, $\mathrm{MAPE}=7,93 \%$, dan $\mathrm{MAD}=85.609,61$ satuan.

\section{Analisis Jaringan Syaraf Tiruan}

Pada tahap analisis jaringan syaraf tiruan proses perhitungan menggunakan software Matlab. Hidden layer yang digunakan dalam penelitian ini adalah 2,3,5,8,10 dan 20. Gambar 6 di bawah ini merupakan pola jaringan syaraf tiruan dengan beberapa layer.

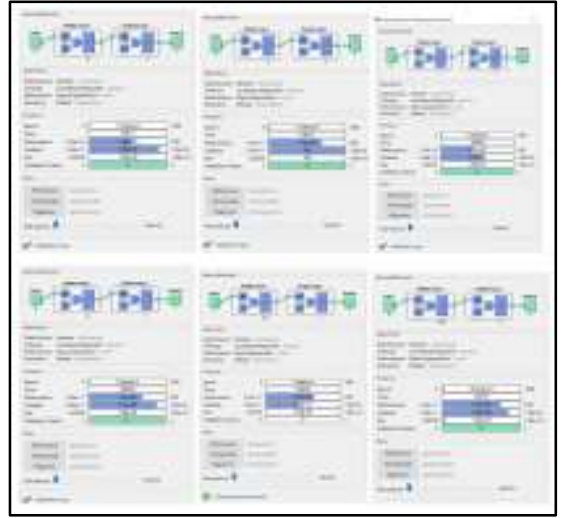

Gambar 6. Iterasi masing-masing hidden layer

Nilai korelasi secara keseluruhan ditunjukkan melalui Tabel 3 dibawah ini untuk masing-masing hidden layer. Nilai tersebut menunjukkan bahwa korelasi mendekati satu sehingga hasilnya sudah sesuai dengan nilai target. 
Tabel 3. Perbandingan hasil nilai $\mathrm{R}$

\begin{tabular}{|c|c|c|c|c|c|c|}
\hline & $\begin{array}{l}\text { anslen } \\
\text { laver } 21\end{array}$ & $\begin{array}{l}\text { Gidden } \\
\text { layer } 3 \text { ) }\end{array}$ & $\begin{array}{l}\text { (habldelen } \\
\text { laver } 5 \text { ) }\end{array}$ & $\begin{array}{l}\text { (thiliten } \\
\text { lower } 8 \text { ) }\end{array}$ & $\begin{array}{l}\text { Cbidden } \\
\text { byer } 199\end{array}$ & $\begin{array}{l}\text { Chidides } \\
\text { tayer 2010 }\end{array}$ \\
\hline $\begin{array}{l}\text { Nilai R data } \\
\text { Training }\end{array}$ & 0.90842 & 0.87103 & 0.88354 & 0.92440 & 0.92638 & 0.95528 \\
\hline $\begin{array}{l}\text { Nilai R Alata } \\
\text { vallotasi }\end{array}$ & 50245 & 7757 & $0.8 \% 979$ & assose & 0.50768 & a.9532s \\
\hline $\begin{array}{c}\text { Nilai R ilata } \\
\text { Test }\end{array}$ & 59 & $y$ & 7 & 0.574 & 12 & 106 \\
\hline $\begin{array}{c}\text { Nilai R } \\
\text { Kendurubail }\end{array}$ & 89162 & 89723 & 0.91241 & 090354 & 0.90505 & 0.97689 \\
\hline
\end{tabular}

Secara umum untuk hidden layer 20 nilai $\mathrm{R}$

\begin{tabular}{|c|c|c|c|c|}
\hline No & Bulan & Aktual & $\begin{array}{l}\text { Prediksi } \\
\text { ARIMA }\end{array}$ & Prediksi JST \\
\hline 1 & Jan-17 & 1.032 .930 & 922.086 & 996.936 \\
\hline 2 & Feb-17 & 957.583 & 1.037 .289 & 1.038 .952 \\
\hline 3 & Mar-17 & 1.066 .588 & 1.049 .828 & 978.698 \\
\hline 4 & Apr-17 & 1.142 .180 & 1.022 .684 & 969.136 \\
\hline 5 & May-17 & 1.150 .067 & 1.059 .173 & 1.046 .313 \\
\hline 6 & Jun-17 & 1.128 .721 & 998.361 & 1.079 .279 \\
\hline 7 & Jul-17 & & 1.029 .330 & 1.079 .279 \\
\hline 8 & Aug-17 & & 1.029 .460 & 1.079 .279 \\
\hline 9 & Sep-17 & & 1.059 .181 & 1.079.279 \\
\hline 10 & Oct-17 & & 1.024 .341 & 1.079.279 \\
\hline 11 & Nov-17 & & 1.019 .947 & 1.079 .279 \\
\hline 12 & Dec-17 & & 1.050 .155 & 1.079 .279 \\
\hline 13 & Jan-18 & & 994.157 & 1.079 .279 \\
\hline 14 & Feb-18 & & 1.054 .613 & 1.079 .279 \\
\hline 15 & Mar-18 & & 1.079 .678 & 1.079 .279 \\
\hline 16 & Apr-18 & & 1.072 .294 & 1.079 .279 \\
\hline 17 & May-18 & & 1.078 .874 & 1.079 .279 \\
\hline 18 & Jun-18 & & 1.060 .258 & 1.079 .279 \\
\hline 19 & Jul-18 & & 1.060 .258 & 1.079 .279 \\
\hline 20 & Aug-18 & & 1.060 .258 & 1.079 .279 \\
\hline 21 & Sep-18 & & 1.060 .258 & 1.079 .279 \\
\hline 22 & Oct-18 & & 1.060 .258 & 1.079 .279 \\
\hline 23 & Nov-18 & & 1.060 .258 & 1.079 .279 \\
\hline 24 & Dec-19 & & 1.060 .258 & 1.079 .279 \\
\hline 25 & Jan-19 & & 1.060 .258 & 1.079 .279 \\
\hline 26 & Feb-19 & & 1.060 .258 & 1.079 .279 \\
\hline 27 & Mar-19 & & 1.060 .258 & 1.079 .279 \\
\hline 28 & Apr-19 & & 1.060 .258 & 1.079 .279 \\
\hline 29 & May-19 & & 1.060 .258 & 1.079 .279 \\
\hline 30 & Jun-19 & & 1.060 .258 & 1.079 .279 \\
\hline 31 & Jul-19 & & 1.060 .258 & 1.079 .279 \\
\hline 32 & Aug-19 & & 1.060 .258 & 1.079 .279 \\
\hline 33 & Sep-19 & & 1.060 .258 & 1.079 .279 \\
\hline 34 & Oct-19 & & 1.060 .258 & 1.079 .279 \\
\hline 35 & Nov-19 & & 1.060 .258 & 1.079 .279 \\
\hline 36 & Dec-19 & & 1.060 .258 & 1.079 .279 \\
\hline
\end{tabular}

Artanti Indrasetianingsih ${ }^{1}$, Ika Damayanti²/ J Statistika: Jurnal Imiah dan Aplikasi Statistika Vol.10, No.2 keseluruhan dan korelasi data training mempunyai nilai tertinggi, sedangkan untuk hidden layer 3 mempunyai nilai $\mathrm{R}$ data validasi dan test yang paling tinggi diantara hidden layer yang lain, tetapi nilai R keseluruhannya paling kecil diantara hidden layer yang lain, yaitu sebesar 0,88723 .

Tabel 4. Data Y test dan hasil prediksi

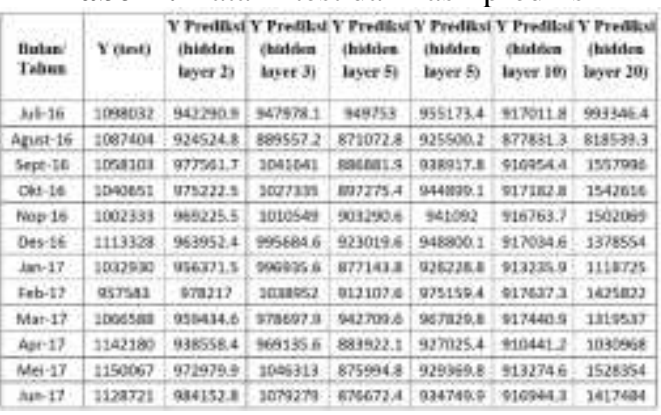

Tabel 4 di atas menunjukkan hasil prediksi backpropagation dari masing-masing hidden layer.

Tabel 5. Perbandingan Ukuran Kesalahan Peramalan

\begin{tabular}{|c|c|c|c|}
\hline $\begin{array}{l}\text { Curra Keselaban } \\
\text { Peramalas }\end{array}$ & MAPE & MAD & MSE. \\
\hline hoblen layer $?$ & 10.45 & 114.724 .57 & 17.859 .297 .547 .91 \\
\hline hidden layer 3 & 3,90 & DS.252,65 & $12.255,475,377,42$ \\
\hline hislan byer 5 & 15.88 & $177.173,09$ & 37.428 .19698475 \\
\hline hisen layer 8 & 12,14 & 133.0127 .27 & $23.132 .987 \times 51.56$ \\
\hline histlen baver 10 & 14.71 & 160513.92 & $31 . \times 63.597500070$ \\
\hline histen layer $20^{\circ}$ & $29.3 \mathrm{~s}$ & $310: 457,8$ ? & 130.421 .286 .102 .65 \\
\hline
\end{tabular}

Tabel 6. Hasil Prediksi ARIMA dan JST

Berdasarkan Tabel 5 dapat diketahui nilai kesalahan peramalan MAPE, MAD dan MSE dari masing-masing hidden layer, agar dapat dipilih hidden layer berapa yang digunakan. Pada penelitian ini digunakan hidden layer 3, dengan nilai kesalahan peramalan terkecil diantara hidden layer yang lain, yaitu MAPE sebesar 7,90\%, MAD sebesar 86.252,66 satuan dan nilai MSE sebesar 12.255.475.337,42. Hasil Prediksi metode JST dengan hidden layer 3 untuk jumlah kunjungan wisman ke Indonesia mulai Januari 2017 sampai Desember 2019 dapat dilihat pada Tabel 6.

\section{Perbandingan Metode ARIMA dan Jaringan Syaraf Tiruan}

Perbandingan hasil prediksi menggunakan metode ARIMA dan JST dilakukan dengan melihat nilai kesalahan peramalan dari kedua metode dan dapat dilihat pada Tabel 7. Tabel 7 menunjukkan bahwa metode ARIMA lebih baik dibanding dengan JST, karena memiliki nilai MAD dan MSE yang lebih kecil dibandingkan dengan JST. 
Tabel 7. Nilai Kesalahan Peramalan MAPE, MAD dan MSE

\begin{tabular}{|l|c|c|}
\hline Metode & ARIMA & JST \\
\hline MAPE & $7,93 \%$ & $7,90 \%$ \\
\hline MAD & $\mathbf{8 5 . 0 6 9 , 6 1}$ & 86.252 .66 \\
\hline MSE & $\mathbf{9 . 1 3 4 . 9 8 1 , 8 0 6 , 9 8}$ & 12.255 .475 .337 .42 \\
\hline
\end{tabular}

Tabel 8 menunjukkah persentase pencapaian total prediksi jumlah kunjungan wisman ke Indonesia pada Tahun 2017 s.d 2019 dengan menggunakan metode ARIMA dan JST terhadap target yang telah ditetapkan oleh Kemenpar. Berdasarkan Tabel 8 dapat diketahui bahwa yang paling mendekati target adalah total prediksi jumlah kunjungan wisman ke Indonesia tahun 2017 dengan menggunakan metode ARIMA, yaitu sebesar $82,01 \%$. Sedangkan untuk tahun 2019 persentase pencapaian prediksi jumlah kunjungan wisman ke Indonesia dengan menggunakan metode ARIMA dan JST sama, yaitu sebesar 64,76\%.

Tabel 8. Target, total prediksi dan persentase

\begin{tabular}{|c|c|c|c|c|c|}
\hline \multirow{2}{*}{ Tahus } & Tarnet & Total I & edilesi & $\% c$ & \\
\hline & Kenserepar & ARIMLS & IST & ARIMA & .5T \\
\hline 2017 & 15 juts & 12301.835 & 9.640 .218 & 82.01 & 64.27 \\
\hline 2018 & 17 juta & $12 \pi 01.420$ & 12.951 .348 & 74,71 & 76,18 \\
\hline 2019 & 20 juts & 12.951 .368 & 12.951 .348 & 64.76 & 6476 \\
\hline
\end{tabular}

\section{KESIMPULAN DAN SARAN}

Kesimpulan dari hasil analisis di atas adalah sebagai berikut :

1. Prediksi jumlah kunjungan wisman ke Indonesia tahun 2017 sampai 2019 dari metode ARIMA dan JST adalah sebagai berikut :

\begin{tabular}{|l|l|r|}
\hline \multirow{2}{*}{ Tahun } & \multicolumn{2}{|l|}{ Total Prediksi } \\
\cline { 2 - 3 } & ARIMA & \multicolumn{1}{l|}{ JST } \\
\hline 2017 & 12.301 .835 & 9.640 .218 \\
\hline 2018 & 12.701 .420 & 12.951 .348 \\
\hline 2019 & 12.951 .348 & 12.951 .348 \\
\hline
\end{tabular}

2. Hasil perbandingan prediksi antara metode ARIMA dan JST menunjukkan bahwa Model model ARIMA $(0,1,1)(0,0,2) 12$ lebih baik digunakan untuk memprediksi jumlah kunjungan wisman ke Indonesia karena memiliki nilai kesalahan peramalan MAD dan MSE yang lebih kecil dibanding metode JST.

Saran yang dapat diberikan adalah sebagai berikut :

1. Sebaiknya dicoba dengan menambah variabel-variabel lain yang diduga dapat mempengaruhi jumlah kunjungan wisatawan mancanegara di Indonesia dan menggunakan metode analisis deret waktu yang lain.

2. Perlu dilakukan analisis dengan metode jaringan syaraf tiruan lainnya misalkan feed forward dan mencoba hidden layer lain untuk mendapatkan kesalahan peramalan yang terkecil.

\section{DAFTAR PUSTAKA}

Anonim, 2016, Konsep dan Definisi Statistik Kunjungan Wisatawan Mancanegara, https://www.bps.go.id/Subjek/view/id/16, Tanggal unduh 29 Mei 2016.

Anonim, 2016, Statistik Wisatawan Mancanegara, http://www.kemenpar.go.id/asp/ringkasan.asp $\underline{\text { ?c=110 }}$

Anonim, 2015, International Tourism Number of Arrivals, http://world-statistics.org.

Anonim, 2013, Urutan kelima komoditas berkontribusi terbesar pendapatan negara, http://www.beritasatu.com/destinasi/90535sektor-pariwisata-sumbang-devisa-negara-8-5miliar-dolar-as.html, Tanggal unduh $28 \mathrm{Mei}$ 2016.

Rukini, Arini,P.S., dan Nawaningsih, E., 2015, Peramalan Jumlah Kunjungan Wisatawan Mancanegara (Wisman) ke Bali Tahun 2019: Metode ARIMA, Jurnal Ekonomi Kuantitatif Terapan, Vol. 8 No. 2, Agustus 2015. http://download.portalgaruda.org/article.p hp? article $=366215 \&$ val $=953 \&$ title $=$ Peram alan\%20Jumlah\%20Kunjungan\%20Wisat awan\%20Mancanegara\%20(Wisman)\%20 Ke\%20Bali\%20Tahun\%202019:\%20Meto de\%20ARIMA, Tanggal unduh 29 Mei 2016.

Wei, W.W.S., 2006, Time Series Analysis Univariate and Multivariate Methods, Second Edition, Pearson Education, Inc., New York.

Wiradinata, S.A., 2011, Model Forecasting Wisatawan Mancanegara ke Provinsi Riau Menggunakan Metode Box-Jenkins, Tugas Akhir, S1, Jurusan Matematika, Fakultas Sains dan Teknologi, Universitas Islam Negeri Sultan Syarif 
Kasim Riau, Pekanbaru.

http://repository.uin-

suska.ac.id/462/1/2011_2011108.pdf,

Tanggal unduh 29 Mei 2016. 
